\title{
LA ECONOMÍA POLÍTICA DE LOS HOSPITALES LOCALES EN LA CATALUÑA MODERNA ${ }^{1}$
}

\author{
Josep Barceló Prats \\ Medical Anthropology Research Center. Universitat Rovira i Virgili (URV) \\ josep.barcelo@urv.cat \\ Josep M. Comelles Esteban \\ Medical Anthropology Research Center. Universitat Rovira i Virgili (URV) \\ josepmaria.comelles@urv.cat
}

Recibido: 30 enero 2015; Aceptado: 26 junio 2015.

Cómo citar este artículo/Citation: Barceló Prats, Josep y Comelles Esteban, Josep M. (2016), “La economía política de los hospitales locales en la Cataluña moderna", Asclepio 68 (1): p127. doi: http://dx.doi.org/10.3989/asclepio.2016.06

RESUMEN: Los hospitales, en Cataluña, se inscribieron desde la Baja Edad Media hasta nuestros días dentro un modelo de gobierno específico que dio lugar a la creación y mantenimiento de una densa red de instituciones asistenciales en prácticamente todos los municipios, incluso en los más pequeños, cuyo marco legal fue el derecho privado o civil. Dicho modelo tiene sus fundamentos, en primer lugar, en la constatación de cómo los individuos legaban al hospital no sólo por la filantropía o caridad, sino también por la necesidad de aportar algo a la comunidad después de su muerte, en una suerte de consigna con el fin de devolver parte de los activos que los testadores habían acumulado durante su vida como instrumento para asegurar la reproducción social de la comunidad. En segundo lugar, se observa que las pequeñas instituciones privadas locales se fusionaron con los hospitales municipales, no así sus activos que continuaron gestionandose por separado de los de la ciudad. En tercer lugar, además de la función de cuidado, el hospital era también un agente económico que operaba de manera similar a los "Monte dei Paschi” italianos. Por consiguiente, el significado de la institución resultó ser más complejo que la simple prestación de servicios asistenciales. Adquirió un valor específico en la identidad de la comunidad, se convirtió en uno de los centros de debate en la vida pública y adquirió un significado económico y financiero que contribuyó a fortalecer la construcción de la identidad colectiva de los ciudadanos.

PALABRAS CLAVE: Hospital; Acción social; Financiación; Cataluña; Asistencia pública.

\section{THE POLITICAL ECONOMY OF LOCAL HOSPITALS IN CATALONIA DURING THE MODERN AGE}

ABSTRACT: ABSTRACT: The aim of this paper is to highlight how hospitals, in Catalonia since the late Middle Ages to the currently, adopted a governance model which resulted in the creation and preservation of hospitals or care institutions in virtually all municipalities, even in small, whose frame legal was the private or civil law. Firstly, we observed how individuals were motivated not only by philanthropy or charity, but also by a need to contribute something to the community after their death, to give back part of the assets the testators had accumulated during their lifetimes, as citizens who had benefited from their positions. Secondly, we observed that the small local private institutions merged with municipal hospitals, but that their assets were managed separately from those of the town. Third, as well as its care function, the hospital was also an economic agent that operated along similar lines to the Italian "Monte dei Paschi". It provided loans to working class citizens at a modest rate of interest. The meaning of the institution was found to be more complex than the simple provision of care services. It acquired a specific value in the identity of the community, it became one of the centers of debate in public life and it took on an economic and financial meaning that strengthened the construction of the citizens' collective identity.

KEY WORDS: Hospital; Social policies; Financing; Catalonia; Public assistance.

Copyright: (C) 2016 CSIC. Este es un artículo de acceso abierto distribuido bajo los términos de la licencia Creative Commons Attribution (CC BY) España 3.0. 
Hace más de un cuarto de siglo, Agustín Rubio Vela (1984) analizó la economía de los hospitales valencianos y puso de relieve como su patrimonio jugó un papel importante en la financiación de la ciudad de Valencia mediante la compra de censales, entre otros productos financieros. Durante la misma década, Terradas (1984, 2005), Ferrer Alòs $(1979,1983,1987)$, Peset \& Graullera (1979) y Tello $(1986,2004)$ exploraron el papel de los censales en la financiación de la Iglesia y de los beneficios eclesiásticos en la Corona de Aragón. EI censal -esto es, la adquisición de una renta tal y como se detallará más adelante - fue una de las principales figuras para la inversión de capitales procedentes de legados, donaciones u otros. La aplicación del resultado de los trabajos citados al caso del Hospital de Valls en Cataluña (Comelles et al., 1991a)², sugirió la hegemonía de la financiación censalista en los hospitales locales del Principado (Comelles et al., 1991b), algo que va siendo ratificado por estudios posteriores, demostrando que dicha preponderancia incluso se perpetuó más allá del final del Antiguo Régimen ${ }^{3}$. El uso del censal conduce a preguntarse por las razones de su uso masivo y a relacionarlo no solo con el significado económico del hospital sino también con su significado social y cultural en la Cataluña medieval y moderna ${ }^{4}$.

Para ello compararemos la documentación de Valls, Sant Feliu de Guíxols, Tarragona, la Santa Creu de Barcelona ${ }^{5}$ junto a otros hospitales locales, con el objeto de desarrollar las bases de un modelo hegemónico de economía política del sistema hospitalario catalán del Antiguo Régimen y su articulación posterior con la economía capitalista.

\section{ORÍGENES Y CONTINUIDAD DE LA GOBERNANZA HOSPITALARIA EN CATALUÑA}

La red de hospitales locales en Cataluña es muy densa desde la Baja Edad media. El inventario de la Generalitat republicana durante la gestación de la Llei de Bases de la Sanitat Catalana, en 19346, demuestra que tres desamortizaciones (Godoy, Mendizábal y Madoz) no solo no liquidaron el dispositivo asistencial, sino que las instituciones provinciales, derivadas de la Ley de Beneficencia de 1849 y del Reglamento de 1852, eran marginales en comparación con las locales ${ }^{7}$. Que éstas pudieran esquivar las desamortizaciones plantea interrogantes no del todo resueltos que remiten a aspectos específicos de las relaciones entre los hospitales, los poderes locales y el Estado antes y después del Decreto de Nueva Planta y de la codificación legislativa del siglo XIX. A nuestro juicio dicha particularidad se enmarca probablemente en la continuidad de la cultu- ra pactista, en la capacidad política de los municipios y en la condición de fundaciones de derecho privado de esos hospitales locales ${ }^{8}$, amparada por la continuidad de usos del Derecho Civil de Cataluña ${ }^{9}$, y que les permitió orillar los intentos de desamortización argumentando su condición de instituciones «privadas».

Tanto es así que en un pergamino recuperado en 2014 y datado a finales del siglo XII, el entonces gobernador del hospital de Tarragona Ponç de Barberà legó un trozo de tierra yerma, propiedad del Hospital de la Seo, en favor de Guillem Maçó y su mujer para que pudiesen trabajarlo $y$, tras cuatro años, pagasen anualmente la novena parte del pan, vino $\mathrm{u}$ otros frutos obtenidos al hospital ${ }^{10}$. Se trata probablemente de un contrato enfitéutico, y es uno de los primeros documentos conservados que desvela el primitivo funcionamiento económico de los hospitales, un siglo antes de la constitución del propio municipio tarraconense, a finales del siglo XIII. Esto es, la financiación del hospital ya se basaba en una red de intereses destinados a asegurar su mantenimiento. Así pues, entre el siglo XII y el XIX, una amplísima documentación pone de relieve un conjunto de prácticas y una cultura financiera que fue hegemónica en la trama urbana de Cataluña. Tendría como objetivo preservar secularmente los dispositivos asistenciales locales incorporados, como piezas indispensables, en la vida cotidiana y en la reproducción del entramado jurídico, económico, político y cultural del comú ${ }^{11}$. Sus fundamentos legales proceden de la continuidad del Derecho romano durante la Alta Edad media ${ }^{12}$, el cual se incorporó como un rasgo cultural e identitario que permitió la confianza en los mediadores jurídicos -jueces, notarios, jurisconsultos- gracias a su auctoritas $^{13}$ basada en el conocimiento jurisprudencial y en la legitimación de sus actos en la resolución de conflictos a lo largo del tiempo. Esta cultura jurídica explicaría su adaptabilidad a los cambios, entre otros tras la peste de 1348, destinados a resolver la crisis financiera de las instituciones mediante «reducciones», esto es, creando nuevas instituciones y uniendo los patrimonios de las precedentes. En Barcelona, Valencia y Zaragoza (Fernández, 1987) dieron lugar a los tres mayores hospitales de la Corona de Aragón, pero sucede lo mismo en Valls, Sant Feliu de Guíxols o Tarragona, entre otras ciudades de menor tamaño.

El instrumento jurídico fue siempre la fundación, por tanto la persona jurídica, amparada por el Derecho privado. Fundadores, donantes y las Universitats eran conscientes de la necesidad de separar la economía de las fundaciones asistenciales respecto de 
los presupuestos municipales, aunque los concejales, en situaciones de crisis, consintiesen la aportación de fondos municipales para evitar bancarrotas. La separación de bienes garantizaba que los legados a los hospitales no se desviasen de la intención de los testadores, ni quedasen sometidos al albur de las luchas políticas locales o de la corrupción ${ }^{14}$. Para combatirlas, los administradores de las instituciones, concejales o miembros de los cabildos, solían ser elegidos por insaculación ${ }^{15}$. La mayoría procedían de la gentry local ${ }^{16}$, bastantes tenían formación jurídica puesto que tenían que administrar legados e intereses de sus pares (Comelles, 2006, pp. 44-52).

Frente al poder civil, el papel de los administradores religiosos debe contemplarse por su condición de albaceas de los legados de las comunidades eclesiales, pero también por la de mediadores desde las direcciones espirituales y los púlpitos, cruciales para alentar limosnas, donaciones y legados de las clases más adineradas. Se confunden el compromiso religioso y el civil (Comelles, 2006, pp. 35-37), puesto que el relato sobre el significado de las fundaciones se vincula a la identidad local. Frente a las interpretaciones genéricas basadas en la caridad y la religión para explicar las fundaciones, la documentación de los hospitales citados pone de relieve que su objetivo era mantener a toda costa un dispositivo de asistencia indispensable para la vida ciudadana. Un buen ejemplo es el de Tarragona (Barceló, 2015).

En efecto, desde la Baja Edad Media el dispositivo de atención a la enfermedad o al desvalimiento se inscribió en un modelo de gobernanza - la res publica, en términos de Eiximenis (1927[1385]) - bajo la hegemonía del poder civil. Se tradujo en la creación y el mantenimiento de instituciones, obras asistenciales y la generalización de la conductio -les conductes del comú ${ }^{17}$ en muchos municipios desde el siglo XIV, con médicos escolásticos, para garantizar su presencia ininterrumpida hasta la creación de los cuerpos de médicos titulares en el XIX.

El Hospital de la Seo tarraconense se fundó en 1171 , con un legado de cien maravedíes en el testamento del arzobispo Hug de Cervelló (Villanueva, 1821, p. 265), y el Hospital Nou de Tarragona, de titularidad municipal, pudo ser una realidad en parte gracias a otro de Francisco Gualtriu en 1441 (Miquel \& Sánchez, 1959, p. 53). Su conversión en activos financieros fue clave para financiar la acción social a largo plazo y asegurar que las instituciones pasasen a ser rasgos de identidad local (Comelles, 2013b, p. 59). Fue así hasta que el 15 de diciembre de 1464 el Arzobispo tarraconense, Pedro de Urrea, fusionó ambos hospitales en el acta fundacional del nuevo hospital: el de Santa Tecla ${ }^{18}$. Este es un buen ejemplo que deja entrever que el control sobre el establecimiento era imprescindible para perpetuar la estabilidad local de un modelo político paccionado y a la vez muy frágil. Con el paso del tiempo, esta forma de gobernar y gestionar la cosa pública fue asumida por la población y, el hospital, garante del sistema, se convirtió en rasgo de identidad local.

Las razones que motivaron esa reducción hospitalaria en Tarragona no difieren de las de otras ciudades ${ }^{19} y$, en parte, tuvo que ver con el mal estado y los deficientes servicios de los dos hospitales fusionados ${ }^{20}$. Pretendía optimizar los recursos existentes y reducir gastos mediante la economía de escala de un único hospital. Pero también confluían la guerra civil catalana y la necesidad de la ciudad de acordar con sus acreedores una serie de medidas para evitar la incautación de la hacienda local ${ }^{21}$. Durante el siglo XV fueron frecuentes estas maniobras para evitar embargos por impagos de la deuda censal (Morelló, 2008). Tarragona, como otras ciudades de la Corona, había hecho lo imposible para reducir su deuda, ponerla bajo control y evitar que se decomisaran las arcas municipales. La espiral de endeudamiento se inició en el siglo XIV y el déficit económico crecía cada año. Los cònsols ${ }^{22}$ intuían que, tarde o temprano, las arcas municipales harían bancarrota y los acreedores, la mayoría foráneos, embargarían los bienes públicos de la ciudad.

La incautación suponía, en la práctica, que los ingresos fiscales del municipio se emplearan en pagar las deudas en lugar de invertirlos en las necesidades de la ciudad. Éste hecho afectaría, de lleno, a los derechos y patrimonio que el municipio tenía sobre el hospital de la misma titularidad, así como con los del hospital de la Seo, puesto que tanto el Arzobispo como el Cabildo estaban también bajo la lupa de sus acreedores. Se optó por blindar el dispositivo de protección social y semanas antes de la quiebra, que se produjo a mediados de 1465, el Arzobispo, con la anuencia de los cònsols, decidió efectuar la fusión para evitar el embargo de los bienes de los dos hospitales, el municipal y el capitular. En resumen, el embargo de las haciendas y de cuanto fuese de titularidad pública o eclesial, suponía una amenaza seria de pérdida del control sobre la gestión y administración del dispositivo hospitalario. Esto era inadmisible para los poderes locales. El dispositivo hospitalario era, para ellos, una fuente de legitimación y el símbolo más notable de un modelo de acumulación 
patrimonial muy arraigado en la sociedad catalana, fruto de la regularidad y la constancia en todos los testamentos otorgados de donaciones y legados destinados al dispositivo. Los ciudadanos asumían, implícitamente, una suerte de legítima destinada a las obras asistenciales.

Para los gobernantes tarraconenses, civiles y eclesiásticos, la mayor capacidad financiera e institucional de los hospitales unificados permitiría, en el futuro, su mejor articulación con la política y la economía locales. El hospital unificado, controlado indirectamente por las autoridades, cobijaba a ciudadanos en dificultades, atendía a vagabundos, extranjeros y enfermos, hacía frente a las crisis sanitarias cíclicas y actuaba como institución de crédito (Comelles et al., 1991a, p. 112). En Tarragona, la amenaza del embargo significaba perder el control del patrimonio del hospital, además de la legitimidad ante los ciudadanos, poque destruía la voluntad expresada por los antepasados, en sus testamentos, de aportar legados para el bien y disfrute de la comunidad doliente. De no garantizarse su inviolabilidad, se torpedeaba la línea de flotación del sistema local de protección social. Había, pues, que garantizar que esos legados continuarían usándose con las finalidades expresadas en las últimas voluntades de los testadores, por muy crítica y angustiosa que fuese la situación económica del municipio. Sólo así, blindando a la institución de aleatoriedades políticas y económicas, podría continuar solicitándose a la ciudadanía, y especialmente a sus elites, una contribución a la acción social.

El instrumento jurídico de la fundación permitía responder a retos coyunturales, garantizaba el blindaje de las intenciones de los testadores e impedía injerencias externas. Los administradores seguían estando habilitados para pedir limosnas o donaciones, incluso obligar a los ciudadanos tarraconenses a testar en favor del hospital con cantidades proporcionales a su patrimonio, según fuesen eclesiásticos, homes de paratge $^{23} \mathrm{o}$ ciudadanos de diversa fortuna ${ }^{24}$.

Tal modelo de gestión, basado en el derecho privado para administrar patrimonios públicos, exigía sistemas rigurosos y profesionalizados de registros contables, de administración y control (López Terrada, 1999), complejos en los grandes hospitales ${ }^{25}$ y más simples en los locales, dónde un administrador delegado estaba a su cargo y pagaba al hospitaler ${ }^{26}$ y a los proveedores. Los médicos eran contratados mediante conductes del comú, que reflejan un precoz proceso de medicalización en las ciudades.

\section{EL REGIMENT DE LA COSA PÚBLICA Y LA ECONOMÍA DE LOS HOSPITALES}

La estructura económica de los hospitales catalanes fue muy estable desde las fusiones medievales hasta más allá de las desamortizaciones y los cambios legislativos del XIX. Su financiación se basaba en la capitalización de donaciones en vida, en limosnas y legados testamentarios de bienes muebles e inmuebles, y en su permanente inversión en tres tipos de productos. Para los legados o donaciones de fincas rústicas o urbanas se utilizaron la enfiteusis (censos) ${ }^{27}$, los censales y más raramente los alquileres. La enfiteusis (cuyas rentas se Ilamaban censos) y los censales ${ }^{28}$ eran formas de préstamo legal durante un periodo ilimitado otorgadas bajo escritura notarial y que comprometían a pagar anualmente un interés ${ }^{29}$. La enfiteusis se aplicaba solo a fincas rústicas, los censales solían gravar fincas urbanas. En caso de cantidades menores, el capital solía retornarse en un plazo de cincuenta a doscientos años (Ferrer Alòs, 1979, p. 39), pues había de ajustarse a lo que el censalista podía pagar sin ir a la ruina ${ }^{30}$. En Cataluña este modelo de financiación lo utilizaron las instituciones asistenciales y los hospitales con el fin de rentabilizar sus legados, limosnas y donaciones. Aunque se trataba de un préstamo, para evitar la interdicción eclesial de la usura, los contratos simulaban una venta, por la cual el que prestaba «compraba» una renta casi vitalicia. Las diferencias entre enfiteusis, censales y los préstamos hipotecarios o bancarios actuales, son notables: aquellos eran rentas fijas muy a largo plazo que aseguraban ingresos regulares prácticamente vitalicios a quién las había "comprado». Era un producto propio de un contexto caracterizado por una baja inflación y la escasez de alternativas (Tello, 1986, p. 47). La expansión de la enfiteusis y de los censales en la Cataluña moderna hizo posible la existencia de una amplia gentry que dependía de esas rentas junto con los alquileres o los servicios profesionales, puesto que parte de ella eran juristas o médicos. Esta gentry fue una relativamente amplia ruling class compuesta por ciutadans honrats, una parte de cargos eclesiales seculares -los beneficiats-, profesionales, mercaderes y artesanos. Sus excedentes los desplazaban hacia ese mercado financiero por su seguridad a largo plazo y el escaso riesgo de la inversión, garantizado por un paraguas legal y una cultura jurídica que aceptaba la mediación profesional de los conflictos. 
La financiación regular de las fundaciones asistenciales se basó hasta el siglo XIX en esas rentas a las que se añadían ocasionalmente subsidios reales o ayudas de los municipios. A veces, la monarquía o el ayuntamiento les concedían el monopolio de loterías, rifas $\mathrm{u}$ otros privilegios como los teatros. Como los hospitales debían acoger sin límites a los demandantes de ayuda, se esperaba de sus familias, especialmente las de los locos internados, hacer aportaciones económicas para su mantenimiento si disponían de recursos.

A finales del siglo XVIII, el Ejército y la Armada empezaron a pagar por día de estancia de soldados y marineros a los hospitales. En Tarragona los primeros pagos por estancia fueron consecuencia de la R.O. del Marqués de la Ensenada de 13 de noviembre de 1748 (Adserà, 1994, p. 26). Con dicha pragmática la Monarquía instauró una nueva manera de financiar la prestación de servicios asistenciales que compensaría en el futuro el aumento del gasto corriente fruto de la implantación de la economía capitalista.

Esta estructura jurídica y económica desarrollada en el Principado no varió, sino que se adaptó, a los cambios legislativos posteriores al Decreto de Nueva Planta y a la centralización de códigos legales (Vilar, 1964-68; Lluch, 1974). En una España, ideológicamente centralista, esto es un particularismo histórico que se puede explicar por las complejas relaciones paccionadas entre las clases dirigentes y el poder municipal en Cataluña y el Estado (Torras Ribé, 2003; Comelles, 2006). Para explicarlo utilizaremos los casos de tres hospitales locales en ciudades pequeñas como Valls,
Sant Feliu de Guíxols y Tarragona, en contraste con el hospital de la Santa Creu de Barcelona.

En la capbrevació ${ }^{31}$ de 1605 , el Hospital de Sant Roc en Valls, una ciudad de unos 2.000 habitantes, poseía más de $86 \mathrm{Ha}$ ( 212 acres) de fincas rústicas y 25 casas, edificios y granjas $^{32}$. La mayor parte del patrimonio rural estaba invertido en enfiteusis, censales o alquileres. Los ocho censos enfitéuticos, rendían un promedio anual de 19'37 sous - casi una libra catalana - mientras que los 58 censales menos de 2'65 sous. Un $50,61 \%$ de todos los ingresos del hospital procedían de los ocho censos y es fácil comprender que la institución prefiriese invertir en ellos los legados en metálico.

En Sant Feliu de Guíxols, provincia de Gerona, la situación era más exagerada. Entre 1728 y 1735, los censos representaban el 93'4\% de los ingresos ordinarios del hospital (Borrell, 2005, p. 16), una ratio muy elevada si se la compara con hospitales fuera de Cataluña donde solía estar por debajo del 10\% (Carasa, 1988). A finales del XVIII, con los intereses al 3\%, aún representaban el $80 \%$ de sus ingresos regulares (Borrell, 2005, p. 21). Aún en la primera mitad del siglo XIX, en la Cataluña capitalista, esas rentas en seis hospitales catalanes suponían más de la mitad de sus ingresos ordinarios ${ }^{33}$.

El empecinamiento de los administradores de los hospitales catalanes en este tipo de rentas, solo puede explicarse por la combinación de confianza y seguridad económica y jurídica a largo plazo que

TABLA 1. Fuentes de ingresos de cuatro hospitales catalanes a mediados del siglo XIX

\begin{tabular}{lcccc}
\hline Concepto & Valls 1847 & Alcover 1847 & Reus 1855 & Manresa 1834 \\
\hline Producto de fincas propias & $49^{\prime} 1 \%$ & $2 \%$ & $42 \%$ & $34^{\prime} 4 \%$ \\
\hline Pensiones de censales & $36^{\prime} 8 \%$ & $65^{\prime} 7 \%$ & $31^{\prime} 7 \%$ & $54^{\prime} 5 \%$ \\
\hline Limosnas & - & $32^{\prime} 3 \%$ & - & $33^{\prime} 5 \%$ \\
\hline Otros $(*)$ & $14^{\prime} 1 \%$ & - & $26^{\prime} 3 \%$ & $7^{\prime} 6 \%$ \\
\hline
\end{tabular}

(*) En el apartado de «otros» se incluyen ingresos por arbitrios, concesiones y otras rentas de carácter diverso.

Fuentes: Para la ciudad de Valls: Arxiu Històric Comarcal de Valls (AHCV), Sección: «Sanitat i Assistència Social». Para el municipio de Alcover: Roca i Girona, Jordi (1984), «Anàlisi del pressupostos del Sant Hospital de pobres de la vila d'Alcover (1847-1863). Algunas consideracions sobre els conceptes de salut i malatia al segle XIX», Butlletí Centre d'Estudis Alcoverencs, 28, pp. 9-36. Para la ciudad de Reus: Anguera, Pere (1990), Hospital de Sant de Reus, Reus, Hospital de Sant Joan de Reus, pp. 63-64. Para el municipio de Manresa: Ferrer Alòs, Llorenç (1987), Pagesos, rabassaires $i$ industrials a la Catalunya Central (segles XVIII-XIX), Barcelona, Edicions de l'Abadia de Montserrat, p. 499. Se puede consultar un cuadro más completo y detallado en: Comelles, Josep M.; Daura, Angelina; Arnau, Marina; Martín, Eduardo (1991), L'Hospital de Valls. Assaig sobre l'estructura i les transformacions de les institucions d'assistència, Valls, Institut d'Estudis Vallencs, p. $200-201$. 
ofrecían para asegurar el gasto ordinario de las instituciones, incluso con la reducción de sus intereses. Las limosnas ocasionales juegan un papel secundario. Los hospitales grandes ${ }^{34}$, en cambio, podían comprar el censal de la ciudad cuando ésta necesitaba financiación ${ }^{35}$, nunca los pequeños. Estos podían comprar censales a particulares que necesitaban capital para financiar gastos, deudas o urgencias derivadas de las crisis de subsistencias más que de necesidades de producción. ${ }^{36}$ Estas necesidades solían ser ocasionales como atender gastos funerarios, pagar el testamento o una dote o adquirir casas, corrales o tierras. Otras eran cíclicas y explican los déficits crónicos y estructurales que convertían a los sectores populares en deudores permanentes de esas instituciones (Ferrer Alòs, 1987, p. 8). Quizás por ello los notarios, en las escrituras de censales, no solían registrar las razones de las demandas relacionadas con la pobreza, la incapacidad de consumo y los problemas de subsistencia.

A pesar de competir en el mismo mercado, el Hospital de Valls colocaba más censales que los beneficios eclesiásticos próximos pero con rentas más bajas que las de éstos.

Según Amelang (1986, p. 24) la demanda de tierras por parte de los artesanos en Cataluña era constante, puesto que les permitía presentarse ante sus vecinos como propietarios (Amelang, 1986, p. 208), y podían financiarlas con censales. La amplitud y la diseminación del mercado de censos y censales colocó a los hospitales en una posición estratégica dentro del sistema crediticio y su embodiment ${ }^{37}$ entre la población fue total. Tanto es así que aquellos que habían tomado créditos del hospital también hacían donaciones en forma de consigna ${ }^{38}$ de tierra o de censales ${ }^{39}$.

A pesar de las apariencias, la economía censalista catalana no era estática, sino una telaraña de transacciones e intereses que se supo adaptar a los cambios económicos. Su estabilidad derivaba de sus garantías jurídicas y de la conciencia por parte de los administradores de que si no se respetaba de modo perenne el objetivo de las donaciones y legados, muchas veces establecidos en las últimas voluntades del testador, sus descendientes no dejarían de reclamar su retrocesión.

La red de la economía censalista se basaba, en buena parte, en mediadores locales, sobre todo notarios, en arenas sociales locales, entre ciudadanos que compartían un conocimiento profundo de los usos y costumbres jurídicos locales. Nada parecido al anonimato del crédito capitalista bancario.
Desde el punto de vista local hay diferencias sustanciales entre el censalista privado, el beneficiado eclesiástico y el hospital. El primero podía aparecer como un escanyapobres ${ }^{40}$, al segundo le legitimaba su condición religiosa y de mediador espiritual, mientras que los hospitales prestaban pero también acogían físicamente a las clases populares en situaciones de crisis. Por eso nos cuesta aceptar la idea del censal como forma de extorsión y preferimos la del censal como forma de redistribución y aseguramiento. Si la donación o el testamento permitían la capitalización del hospital, la economía censalista permitía mantenerlo y asegurar sus prestaciones en una sociedad ajena al aseguramiento capitalista o mutualista posterior. Tanto es así, que la telaraña censalista desbordaba los límites del término municipal en donde se ubican los hospitales, poniendo de relieve, en los hospitales locales, un hinterland ${ }^{41}$ comarcal de intereses compartidos, muy visibles en Valls, Sant Feliu o Tarragona; y que en la Santa Creu de Barcelona - un hospital de referencia-, desbordaba los límites del Principado, hecho que explica la complejidad de sus ingresos.

La concentración de patrimonio en torno a los hospitales era una estrategia económica, política y social de la cual no conocemos todavía el cuadro completo. Intuimos un papel en la regulación del mercado inmobiliario, puesto que, aunque había legados inalienables, la documentación pone de relieve que el saber jurídico de las administraciones les permitía tomar censales o censos, efectuar permutas y otras prácticas de compra y venta documentadas por la fe pública, en los límites de las cláusulas de los legados mediante una interpretación flexible del Derecho (Comelles, 2006, pp. 40-158). A su vez, la telaraña censalista y de intereses financieros de los hospitales ponía también de relieve su papel en la vertebración de la res pública local en la medida que, junto al mecenazgo de la gentry, los protocolos notariales conservan miles de testamentos de las clases populares con recursos modestos a las instituciones. Tanto es así que los notarios catalanes consideraban esos legados "de algo" para el hospital, una clàusula d'estil ${ }^{42}$. "Algo» podían ser unos sous o simplemente un colchón. "Algo» es la forma como se expresa la participación del conjunto de la ciudadanía en el regiment de la cosa pública cuando se tiene asumida e interiorizada una cultura jurídica y política que permite confiar en el buen destino de su legado y que expresa la conciencia de una responsabilidad colectiva en relación al comú y, especialmente, a los colectivos más vulnerables. 
TABLA 2. Censales creados a favor del Plato de los Pobres Vergonzantes y del Hospital de Valls según las profesiones agrupadas por censatarios (1442-1629)

\begin{tabular}{lcccc}
\hline PROFESIÓN & Censales & $\begin{array}{c}\text { \% de censales } \\
\text { comprados }\end{array}$ & $\begin{array}{c}\text { Capital } \\
\text { (sous) }\end{array}$ & $\begin{array}{c}\text { \% que supone el capital respecto } \\
\text { el total }\end{array}$ \\
\hline Artesanos & 23 & $46^{\prime} 9 \%$ & $388^{\prime} 60$ & $43^{\prime} 12 \%$ \\
\hline Payeses & 8 & $16^{\prime} 4 \%$ & $255^{\prime} 60$ & $28^{\prime} 35 \%$ \\
\hline Comerciantes & 2 & $4^{\prime} 1 \%$ & $150^{\prime} 10$ & $16^{\prime} 67 \%$ \\
\hline Desconocida & 16 & $32^{\prime} 6 \%$ & 107 & $11^{\prime} 87 \%$ \\
\hline TOTAL & 49 & $100 \%$ & $901^{\prime} 30$ & $100 \%$ \\
\hline
\end{tabular}

Fuente: Arxiu Històric Comarcal de Valls (AHCV).

En líneas generales las deudas que motivan la venta de censales al hospital solían ser debidos a déficits de subsistencia más que a necesidades de créditos para la producción. Al lado de las dificultades momentáneas a las que se suelen hacer referencia en las cartas de creación de censales, son muy importantes las necesidades cíclicas desencadenantes de un déficit crónico y estructural que conducía a algunos grupos a endeudarse permanentemente. Seguramente por éste hecho un número considerable de cartas de creación de censales, casi un 47\% según los datos de Valls para éste periodo, los censatarios dejan en secreto las razones de la venta del censal, y esto no deja de ser una manera de esconder la pobreza vergonzante.

TABLA 3. Censales creados en la ciudad de Valls (1335-1629), según el censalista y el capital comprado

\begin{tabular}{lcccc}
\hline CENSALISTA & Censales & $\begin{array}{c}\text { \% de censales } \\
\text { comprados }\end{array}$ & $\begin{array}{c}\text { Capital } \\
\text { (sous) }\end{array}$ & $\begin{array}{c}\text { \% que supone el capital } \\
\text { respecto el total }\end{array}$ \\
\hline Hospital & 49 & $30^{\prime} 6 \%$ & $950^{\prime} 70$ & $8^{\prime} 29 \%$ \\
\hline $\begin{array}{l}\text { Comunidad de } \\
\text { presbíteros }\end{array}$ & 31 & $19^{\prime} 3 \%$ & $2.188^{\prime} 15$ & $19^{\prime} 07 \%$ \\
\hline $\begin{array}{l}\text { Jurados de la villa } \\
\text { Particulares (laicos) }\end{array}$ & 1 & $0^{\prime} 6 \%$ & $60^{\prime} 00$ & $0^{\prime} 52 \%$ \\
\hline $\begin{array}{l}\text { Particulares } \\
\text { (eclesiásticos) }\end{array}$ & 54 & $33^{\prime} 7 \%$ & $7.218^{\prime} 60$ & $62^{\prime} 91 \%$ \\
\hline Otras Obras pías & 14 & $8^{\prime} 7 \%$ & $936^{\prime} 00$ & $8^{\prime} 15 \%$ \\
\hline TOTAL & 11 & $77^{\prime} 1 \%$ & $120^{\prime} 73$ & $1^{\prime} 06 \%$ \\
\hline
\end{tabular}

Esta tabla demuestra como el principal censalista de la ciudad de Valls era el hospital de la propia ciudad, con un 30 '6\% de los censales comprados. Le seguían la Comunidad de presbíteros y los eclesiásticos, a título particular, con un $28 \%$. Finalmente, los censalistas laicos particulares allegaban un 33'7\% por lo que hace referencia al número de préstamos concedidos. Los restantes censales, correspondientes a las Obras Pías de la ciudad, tenían una importancia ciertamente secundaria. Aunque el hospital hace más préstamos que la Comunidad de presbíteros, su valor (hablando en términos de capital) es sustancialmente menor. Esta diferencia es un indicio que explica la diferente funcionalidad y significación social de una y otra institución en sus actividades como censalistas.

Fuente: Arxiu Històric Comarcal de Valls (AHCV). Se puede consultar un cuadro más completo y detallado en: Comelles, Josep M.; Daura, Angelina; Arnau, Marina; Martín, Eduardo (1991), «L’hospital com a institució de crèdit: el cas de l’hospital de Valls». En: Jordà, Antòn (ed.) Quaderns d'Història Contemporània. Homenatge a María Antonia Ferrer Bosch, Lleida: Poblagrafic, pp. 45-71, p. 49. 
GRÁFICO 1: Área de influencia geográfica del mercado censal del Hospital de Tarragona (1599-1600)

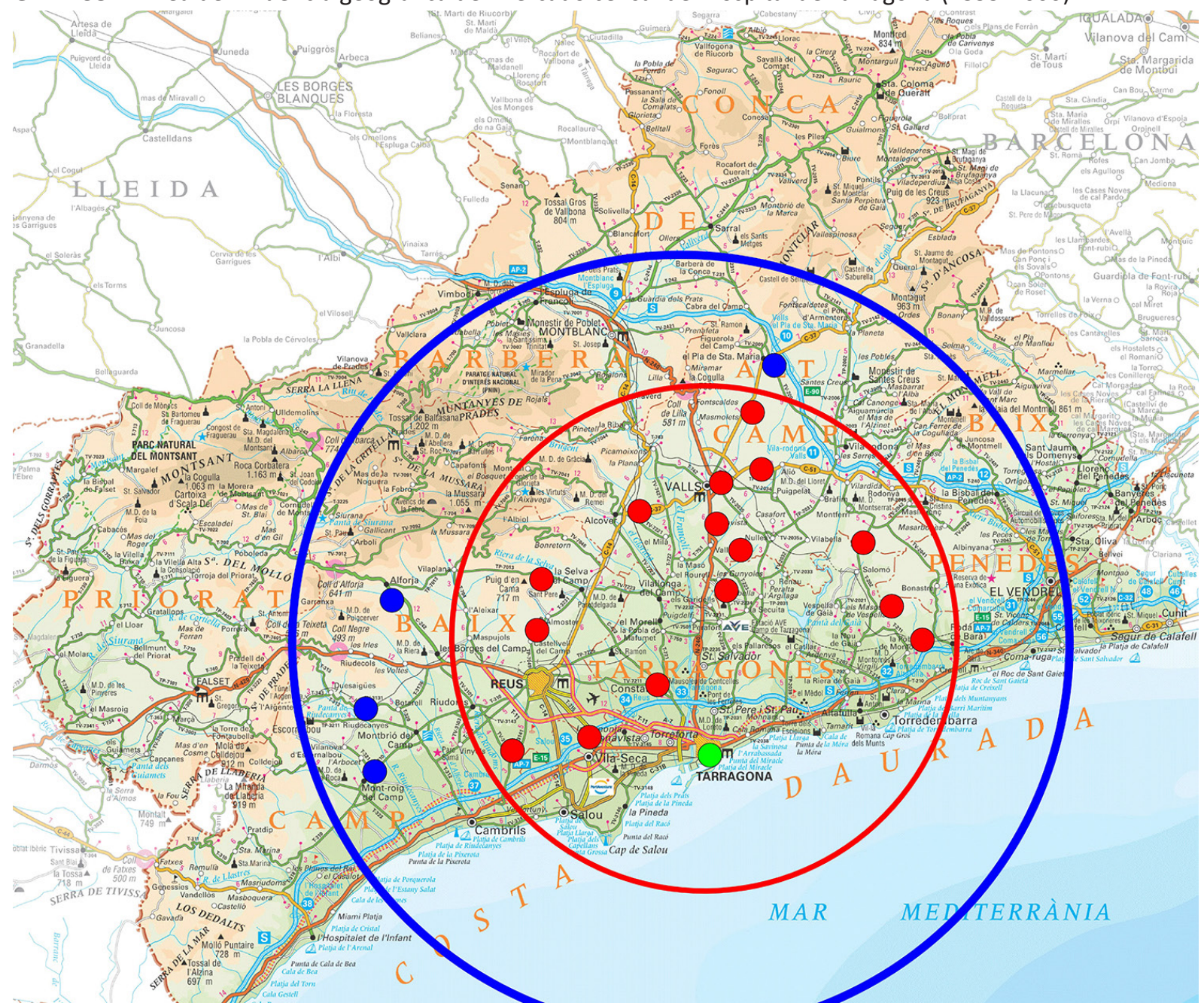

Fuente: Barceló, Josep (2014) Poder local, govern i assistència pública: el cas de Tarragona, Tarragona, Universitat Rovira i Virgili, p. 170.

Es interesante comprobar la proximidad geográfica de la mayoría de personas que encargaban censales al hospital. Lógicamente, la ciudad que concentraba buena parte de la demanda de censales al hospital, por parte de personas físicas, era la capital Tarragona [en verde]. Pero no es casual comprobar cómo, de los restantes 19 municipios que figuran al gráfico, y en los cuales se registran encargos de censales por parte de particulares al hospital, 15 poblaciones (Altafulla, Cambrils, el Catllar, Constantí, Maspujols, el Morell, Riudoms, el Rourell, la Selva del Camp, Torredembarra, Vallmoll, Valls, Vilafortuny, Vilallonga y Vilaseca) están situadas en un área geográfica de máximo 20 kilómetros respecto a la capital [en rojo]; y los restantes, concretamente, Alforja, Mont-roig, Pla de Cabra y Riudecanyes, están ubicadas a no más de 30 kilómetros [en azul]. Se hace evidente que el entramado económico del sistema censalista se construía sobre una red de proximidad, la cual era imprescindible para un patrón económico que operaba sobre la base de relaciones de reciprocidad i no detrás del anonimato del crédito capitalista basado, actualmente, en el modelo bancario.

Esta conciencia local del valor del dispositivo asistencial catalán explica, desde finales del XVIII, la resistencia de los municipios a las desamortizaciones o a los intentos de desmontar los dispositivos hospitalarios locales para transferirlos a hospitales del corregimiento o provinciales. Las resistencias expresan la negativa a perder un servicio de proximidad frente a una institución lejana, y la consciencia de que el patrimonio asistencial es el fruto de un compromiso secular de la ciudadanía.

\section{DE LA ECONOMÍA CENSALISTA AL CAPITALISMO}

Cuando los Borbones redujeron los intereses de censos y censales al $3 \%$, los ingresos ordinarios de muchos hospitales locales sufrieron mermas de hasta un $40 \%$. Los Borbones querían castigar a los rentistas menos afectos a la dinastía, pero la medida afectó sobre todo a los hospitales locales. Les supuso refinanciar inversiones lo que se tradujo, básicamente, en la luición de 
Tabla 4. Presupuesto del Hospital de la Santa Creu de Barcelona en el año 1847

\begin{tabular}{lcc}
\hline Concepto & Capital (reales de billón) & Porcentaje \\
\hline alquiler fincas urbanas & 383.389 & $55^{\prime} 1 \%$ \\
\hline Producto fincas rústicas & 155.190 & $22^{\prime} 3 \%$ \\
\hline Pensiones de censales & 140.304 & $20^{\prime} 1 \%$ \\
\hline Rentas diversas & 17.470 & $2{ }^{\prime} 5 \%$ \\
\hline Total & 696.353 & $100 \%$ \\
\hline
\end{tabular}

Fuente: Pérez, Manuel (2003), La privatització de la follia: I’assistència psiquiàtrica a Catalunya durant el segle XIX, Barcelona, Publicacions de l'Abadia de Montserrat, pp. 35-36.

Las singularidades de financiación de los grandes hospitales, como muestra este ejemplo del Hospital de la Santa Creu de Barcelona a mediados del siglo XIX, se fundamentan en que, además de ser receptores de grandes subvenciones por parte de los poderes públicos, disponían de un radio de influencia geográfica superior al resto de hospitales locales, hecho que les otorgaba una mayor capacidad de recibir donaciones, legados o limosnas, entre otros bienes, y la consiguiente acumulación de capital permitía a los administradores diversificar sus inversiones. Todo ello, daba a la institución una mayor independencia respecto de las rentas provenientes de los censales. Esta situación queda reflejada en la presente tabla, puesto que sólo una quinta parte del total de ingresos de la Santa Creu, para el año 1847, provenían de pensiones de censales. Sin embargo, la realidad financiera para la mayor parte de hospitales catalanes de la época, sobre todo los de menor tamaño, era radicalmente opuesta.

censales y la obligación de diversificar sus inversiones (Ferrer Alòs, 1987, p. 493). En la segunda mitad del XVIII, la especialización de los hospitales locales y la necesidad de nuevos reglamentos que se adaptaran a las medidas técnicas, supusieron un incremento del gasto corriente de farmacia y médicos y, también, del aumento de la demanda de internamiento. Esta transición desbordaba la rigidez del modelo de financiación precedente. Aunque a finales del XVIII los gremios de algunas ciudades catalanas desarrollaron formas incipientes de seguros médicos para sus afiliados (Zarzoso, 2006) estos no pudieron generalizarse hasta finales del XIX. Sin embargo, en los hospitales medianos como Tarragona, o en los grandes como Barcelona, el pago por estancia, aunque contradictorio con la política de puertas abiertas de los hospitales, se fue implantando a medida que los administradores reclamaban a ciertos colectivos ese tipo de retribución a sus servicios.

En 1796, Godoy, decretó una desamortización de los bienes de las instituciones asistenciales. Pretendía vender el patrimonio a particulares y crear un fondo de compensación que rendiría un 3\% sobre el capital aportado. Pretendía financiar la Guerra Gran (1794-96) y copió la política de la Convención francesa, cuando esta ya se había visto obligada a revertirla ante el fiasco económico y asistencial de las instituciones $^{43}$. Godoy ignoró el fracaso francés y desmontó las bases financieras de la acción social aunque, por razones nunca del todo explicadas, no se aplicó a los bienes de los hospitales catalanes ${ }^{44}$, quizás porque su condición de fundaciones reguladas por el derecho privado catalán las dejaba al margen ${ }^{45}$.

Hasta la Desamortización de Madoz, en 1854, los hospitales catalanes vivieron en una suerte de limbo jurídico que permitió su subsistencia, a cambio de una crisis de recursos en un contexto muy complejo. A saber, Cataluña estuvo en estado de guerra entre 1794 y 1796 ; entre 1808 y $1814^{46}$; en Guerra Civil de 1833 a 1839; fue provincia del Imperio francés de 1809 a 1814; asumió la Constitución Liberal española de 1812 a 1814; la vuelta al absolutismo entre 1814 y 1820; un paréntesis constitucional hasta 1823; y una década de absolutismo hasta 1833. En ese medio siglo, los hospitales catalanes mantuvieron su autonomía financiera gracias a la práctica del regiment de la cosa pública, y a la responsabilidad municipal en relación a la tutela y asistencia a los desvalidos, pero todo ello a costa de asumir un creciente gasto corriente. Esto obligó a los municipios, ante la crisis de rentas regulares, a destinar partidas, subvenciones o servicios para cubrir déficits, especialmente, en hospitales pequeños.

Como la Ley de Beneficencia en 1822 nunca llegó a aplicarse, no fue hasta la de 1849 , con su Reglamento de 1852 y la desamortización de Madoz que no cambió la situación de los patrimonios hospitalarios. Con todo, la nueva reglamentación no propició, al contrario de lo que sucedió en Castilla, la creación de 
manicomios u hospitales provinciales. Esta Desamortización liquidaba los patrimonios de las instituciones locales incluidos la redención (lluïment) de censos y censales a muy bajo costo. A cambio el Tesoro Público ofrecía a las instituciones unas rentas equivalentes en forma de bonos del Estado. Sus efectos fueron demoledores como demuestra el caso de Valls cuyo hospital se financiaba hasta entonces de modo autónomo.

Los administradores de Valls pidieron al Gobierno de España que las declarase exentas de impuestos y tasas porque «la cancelación de los censales [por la Desamortización] les condujo a una reducción de ingresos tal que impedía pagarlas ${ }^{47}$. Aunque el Tesoro había pagado 2.926 reales y 20 céntimos por los activos y censales $^{48}$, estas cantidades eran muy inferiores a los ingresos que recibía antes el Hospital por los censales que había tomado y que en 1847 ascendían a 8.491 reales. En 1860 el hospital ya había vendido sus propiedades urbanas y rústicas; y unos ingresos por rentas de 16.000 reales habían quedado reducidos a menos de $3.000^{49}$. Por esa razón el Hospital «no podía responder a sus necesidades $»^{50}$. Como la amortización de los bonos del Estado fue siempre problemática por su debilidad financiera (Rovira, 1990: 233-243), las instituciones se vieron obligadas a buscar recursos en otros lugares.

La legislación centralizadora jamás se compensó con compromisos financieros del Estado y dejó el dispositivo asistencial local catalán en una situación crítica. Sobrevivieron por la diversificación de sus recursos a partir de subvenciones o concesiones. En Valls fundaron una fábrica de harina ${ }^{51}$ y un teatro $0^{52}$, y obtuvieron la concesión de las aguas ${ }^{53}$. En Sant Feliu de Guíxols y en Tarragona tenían concedidos además los cementerios, y en la Santa Creu de Barcelona y en Santa Tecla de Tarragona desarrollaban el pago por estancia en dementes, militares e incluso pacientes privados, además de la explotación del teatro y otros privilegios. Con el paso del tiempo, Sant Feliu y la Santa Creu optaron por reforzar aún más su carácter privado para evitar las desamortizaciones (Comelles, 2006, pp. 78-82) y otras políticas descapitalizadoras, aunque esto dificultaba el traspaso a los municipios de partidas presupuestarias.

\section{CONCLUSIONES}

Si un viajero se acerca hoy a Cataluña y visita su red de hospitales comarcales, podrá comprobar que en Puigcerdà, Vilafranca, Valls, Reus, Tarragona, Manresa, Vic, Girona, Lleida y muchas otras pequeñas ciudades, las fundaciones medievales representan más de la mitad de la red hospitalaria. Han sobrevivido a tres desamortizaciones, a nueve cambios constitucionales mayores, tras la abolición de las constituciones catalanas, a dos guerras internacionales, a dos invasiones y a cuatro guerras civiles. Pese a los esfuerzos centralizadores del estado, desde 1716, las fundaciones catalanas continúan su tarea de provisión de servicios vinculadas a los municipios y lo que es más importante, conservando, con las adaptaciones necesarias, su significado en la identidad cultural local. Bien es cierto que algunos hospitales, como la Santa Creu, malversaron parte del patrimonio heredado y algunos aún redimen censales para convertirse en proveedores puros de servicios basados en el pago por estancia.

El argumento que hemos mantenido y tratado de mostrar es que la continuidad de los hospitales locales catalanes se explica por la persistencia de una cultura económica-política y comunitaria, el regiment de la cosa pública, definida en la Baja Edad Media y que ha vertebrado la vida de la comunidad y ha permitido asegurar su existencia, adaptándose a las coyunturas económicas, políticas o sociales e incluso a los cambios en la función asistencial del hospital, desde la tutela medieval al hospital público de servicios actual (Comelles, 2014). Significa que los hospitales nacieron de la comunidad para la comunidad y ha sido la comunidad la que, de modos distintos, con aportaciones distintas afianzó su significado y aseguró su futuro, a partir de la defensa de su autonomía y de una construcción legal y jurídica que ha garantizado su continuidad ${ }^{54}$. Permitió alcanzar este objetivo, una práctica económica y política basada en una «cultura», construida sobre la garantía que tradicionalmente ofrece el Derecho y sus mediadores: juristas, notarios y jueces sensibles a los usos y costumbres locales.

En un libro reciente, Louis Assier-Andrieu compara la common law anglosajona y los sistemas de derecho continentales napoleónicos modernos. Para explicar la persistencia de la primera hoy, dicho autor parte del valor que la common law atribuye a la autoridad del pasado lo que se traduce en formas culturales que son en sí mismas dinámicas. En la cultura jurídica y política local catalana, heredera del Derecho Romano, la «autoridad del pasado» entendida como jurisprudencia o como fuente de ideas para la resolución caso a caso de situaciones locales, a menudo nuevas, creemos que ha sido fundamental para explicar la persistencia en el tiempo de las fundaciones hospitalarias. El respeto inalienable a la voluntad de los legatarios, la confianza en el papel de mediación de la fe pública y la confianza en el derecho permiten resolver problemas y encontrar remedios, si conviene, forzando 
los límites jurídicos o asumiendo que la experiencia del pasado puede contribuir a imaginar soluciones jurídicas para resolver situaciones singulares y culturalmente aceptables. Esa jurisprudencia pasada ha servido para imaginar respuestas a la incertidumbre que significaba la transición del antiguo régimen al capitalismo, a los intentos centralizadores del estado o a la transición del hospital rentista y de beneficencia a la empresa de servicios que es hoy. Todo ello no ha significado jamás una privatización de lo público en términos actuales, puesto que las instituciones asistenciales han sido siempre públicas aunque bajo la

\section{NOTAS}

1. Este texto deriva del trabajo de Comelles (2013a) junto con la tesis de doctorado de Barceló (2014). Éste último trata sobre un amplísimo estudio de caso sobre el Hospital de Sant Pau y Santa Tecla de Tarragona que, por la calidad y la cantidad de la documentación, permitió resolver algunos de los interrogantes que la relativa modestia de los fondos otros hospitales locales impedían contestar. El punto de partida de ambos proyectos fue, aproximadamente, hace un cuarto de siglo con el estudio de un hospital local, el Pius Hospital de Valls (Comelles et al., 1991a). Nuestro más sincero agradecimiento a las siguientes personas, sin cuya colaboración el presente artículo no sería una realidad: Sílvia Alemany, Marina Arnau, Jon Arrizabalaga, Antoni Conejo, Coral Cuadrada, Angelina Daura, Reis Fontanals, Laura Francès, Manel Fuentes, Teresa Huguet, Eduardo Martín, Pilar Salmerón, Neus Sánchez, Teresa Viñoles y Alfons Zarzoso.

2. Los ejes de estudio del mismo fueron más tarde desarrollados en Comelles (2006) y, también, en Comelles et al. (2013b).

3. Un amplio y detallado estado de la cuestión se puede encontrar en Conejo (2010) y López Terrada (1999). Una problemática similar, por lo que sugiere un abordaje comparativo no realizado hasta el momento, ha sido estudiada en los hospitales y monte dei paschi italianos bajomedievales. A tales efectos, véase: Grieco et al., (1997), Henderson (2001), Diana (2010) o, por citar un último ejemplo, Marino (2014).

4. Aunque existe numerosa literatura sobre hospitales reales en Castilla, por ejemplo: Valenzuela, et al., (2008); López Alonso, (1988); García Guerra, (1983); Zamorano, (1997); sin embargo, por lo que se refiere a estudios de hospitales locales y para época moderna no se han podido encontrar suficientes datos para poder establecer un estudio comparativo entre el caso de la Corona de Aragón, planteado en el presente artículo, y el caso de Castilla, aunque si referencias sustanciales para edad contemporánea, disponibles en: Carasa \& Enciso (1985); Carasa, (1990: 425-452). Un re- tutela del Derecho privado. Esto fue y en buena medida continúa siendo necesario para mantenerlas al margen, en la medida de lo posible, de los avatares políticos. El concepto de fundación que las sostiene hace que no sean de nadie y que sean de todos, de los que las fundaron, de los que legaron, de los que tomaron censales para asegurar su mantenimiento, $y$ de los que en tiempos recientes exigieron su mantenimiento local, por ejemplo en Valls, porque querían que sus hijos naciesen y sus deudos fuesen acogidos en sus crisis o en sus horas finales en una institución que consideraban prolongación de sus casas.

ciente estado de la cuestión sobre del sistema hospitalario español, se puede encontrar en: Huguet, et al., (2014).

5. El estudio de los censales y de la documentación económica del Hospital de la Santa Creu de Barcelona trasciende el marco estrictamente local, puesto que permite documentar una amplia red de relaciones de dependencia que involucra otras localidades catalanas y de fuera de Cataluña, como es el caso de Mallorca (Morelló, 2014). De la época bajomedieval solo se ha conservado, que se sepa, un único libro de cuentas, correspondiente al ejercicio de 14301431, objeto de un primer análisis por Fernández Sevillano (2003). Sobre posibles compras de censals morts, la documentación aportada por Castejón, Natividad (2007) puede ser de utilidad.

6. Consultar el Arxiu Nacional de Catalunya (ANC): «Fondo Generalitat republicana».

7. Algunas de estas instituciones disponen de monografías tales como, por ejemplo: Anguera (1990), Borrell (2005), Cid et al., (1993), Danón (1978), Pladevall (2000) o Reventós (1996).

8. Sobre las relaciones entre la cultura jurídica romana y las fundaciones hospitalarias, véase: Miller (1997), Imbert (1947) y Ourliac (1989). Sobre el papel del Derecho romano en Cataluña, véase: Assier-Andrieu (1989).

9. Los usos y las costumbres locales estaban reflejados en las Constituciones catalanas. Sin embargo, la abolición de éstas con la instauración del Decreto de Nueva Planta no supuso, a nivel práctico, la desaparición del derecho civil catalán. Para una aproximación coherente a la continuación del derecho catalán en la configuración de la vida política i civil catalana después del Decreto de Nueva Planta, véase: Fontana (2014).

10. Consultable en: Arxiu Històric de l'Hospital de Sant Pau i Santa Tecla (AHSPT). 
11. El término comú, designaba en Cataluña y en la Andorra actual el municipio como colectivo humano. A tales efectos véase la definición que hacía de dicho concepto el franciscano Francesc d'Eiximenis ya en 1385 (Eiximenis, 1927). En cambio el término para referirse al Ayuntamiento, en época medieval y moderna, fue la Universitat y para los cargos municipales existe diferente terminología según las diferentes áreas geográficas de la Corona de Aragón. Así, pues, en Tarragona se designaban como cònsols; en BarceIona como consellers; en Lleida como paers; o en Valencia como jurats.

12. Véase: Salrach, $(1987,2013)$, Constantelos $(1968,1992)$, Bonnassie (1979-1981) y Patlagean (1977).

13. El término auctoritas aparece en Roma ligada a la función tutelar. Sin embargo, en Derecho romano se entiende por auctoritas una cierta legitimación socialmente reconocida, que procede de un saber y que se otorga a una serie de ciudadanos. Ostenta la auctoritas aquella personalidad o institución que tiene capacidad moral para emitir una opinión cualificada sobre una decisión. Si bien dicha decisión no es vinculante legalmente, ni puede ser impuesta, tiene un valor de índole moral muy fuerte. El término es de difícil traducción en lengua castellana, puesto que la palabra «autoridad», como vocablo más cercano, apenas posee las verdaderas connotaciones de la palabra latina.

14. Véase: Risse (1999) y Freidson (1963).

15. Sobre el municipalismo en Cataluña, véase: Torras Ribé (1983); y Juncosa (2014) para el caso más concreto de Tarragona.

16. Concepto que en el caso de Cataluña se usa para referirse esencialmente a la nobleza de tipo medio y bajo (barones, caballeros...) y a los hombres libres terratenientes que, comúnmente, se han englobado bajo la etiqueta de burguesía territorial. Para saber más sobre dicha clase dirigente en Cataluña, véase: Amelang (1986).

17. La conductio -en catalán les conductes del comú- eran contratos entre las Universitats y los médicos escolásticos para asegurar su presencia en la ciudad. Sobre los orígenes de estas prácticas en la Corona de Aragon, véase: García Ballester et al., (1989) y, a nivel europeo, Nutton $(1977,2004)$.

18. La copia de la escritura de fundación se puede consultar en el Arxiu de l'Hospital de Sant Pau i Santa Tecla (AHSPT), "Hospital de pobres enfermos de la ciudad de Tarragona. Libro coordinado a fines del año 1837. Caja 42, núm. 586, anexo núm. 2».

19. Como la Santa Cruz de Barcelona (1401) y Santa María de Lleida (1453).

20. «En Tarragona existen el Hospital de la Seo, el otro el Hospital Nuevo de la ciudad, que no son suficientes para las necesidades de los pobres que concurren, por falta de asistencia hospitalaria, de forma que los dos están mal atendidos.» (Cubells, 1989, p. 3).
21. La Guerra Civil catalana, (1461-1472), acabó con el triunfo de la monarquía y con la renovación del modelo censualista vigente hasta el XIX. A efectos de la hipótesis expuesta, este evento reforzó, aún más, los derechos de los acreedores. Sobre el conflicto civil en Tarragona, véase: Sobrequés \& Sobrequés (1973).

22. Cargo con que se designaba a los magistrados de Tarragona que poseían las facultades rectoras y ejecutivas del municipio. Véase nota número 11.

23. En el Principado de Cataluña y el Reino de Valencia, hasta el siglo $\mathrm{XV}$, el término home de paratge se refería a una persona con un linaje conocido, generoso, honesto e incluso militar que disponía de un patrimonio suficiente para no tener que dedicarse a trabajos manuales o mecánicos y que, además, era apto para ser nombrado caballero puesto que disponía de caballo y armas en caso de ser llamado por el soberano (aunque a priori no era un profesional de la milicia). Aunque no constituían ningún estamento propio dentro de la jerarquía social de la época, eran considerados como la más pequeña nobleza de carácter rural.

24. Sobre la estructura social de Tarragona en la Baja Edad media, véase: Cuadrada (2003).

25. El Hospital de la Santa Creu de Barcelona es el mejor ejemplo de una institución con una organización hospitalaria compleja. Para una aproximación a su estructura de gestión, véase: Comelles (2006, pp. 44-69) y Danón (1978).

26. El hospitaler era la persona a cargo de la vida cuotidiana del hospital, ayudado por criados y criadas, y solía vivir en la institución.

27. En Castilla los censos eran llamados juros. En general censales y juros daban mayor rendimiento que los alquileres, salvo en los de regadío.

28. En el derecho catalán, el censal era un instrumento crediticio basado en el derecho a pagar una pensión anual a cambio de un capital. Si se quería dejar de pagar la renta anual, se podía recomprar el capital (luición). El resultado era un préstamo a perpetuidad. Enfiteusis significa que un dominio privado se podía dar a un usuario a cambio de un canon o censo. Véase: Ferrer Alòs (1983, pp. 101-128; 1987).

29. Las tasas de interés eran el $7^{\prime} 14 \%$ en el siglo XIV, $5 \%$ en el XV, $6^{\prime} 66 \%$ en el XVI, $5 \%$ en el XVII y el $3 \%$ en el XVIII. Véase: Ferrer Alòs (1987, p. 492). Con la crisis del Antiguo Régimen, el censal dió paso a formas de préstamo más cercanas a la usura, como la venta por carta de gracia o el debitori. Véase: Ferrer Alòs (1983: 111-113), Soronellas (1990, pp. 8-9).

30. El sistema dio lugar a deudas crónicas, tal y como describe Ferrer Alòs (1987, p. 32).

31. Un capbreu es el documento que contenía las declaraciones de bienes hechas por los vasallos de un señorío, y las 
cargas que conllevaban, ante un notario designado por el señor feudal con la finalidad de registrarlas. Por consiguiente, una capbrevació era el reconocimiento del dominio y de las prestaciones inherentes a éste que el enfiteuta hacía al señor directo.

32. Arxiu Històric Comarcal de Valls (AHCV), «Secció de Pergamins».

33. Las diferencias se explican localmente. En Castilla, Carasa (1987, p. 380) afirma que los intereses eran del 6\% a finales del XVIII. Fernández (1987, pp. 156-159) encontró que eran del 3'6\% en 1767. En el General de Valencia (184447) estaban al 4'9\%. Estas cifras revelan la crisis del sistema en Castilla y el País Valenciano, desde principios del siglo XVIII, a diferencia del caso catalán. Véase: Peset \& Graullera (1979, pp. 107-138).

34. Tarragona, actuaba con dinámicas de ciudad-capital puesto que era el centro neural de una densa red de pueblos. Por eso, en 1837 , sólo el $20 \%$ de sus ingresos del hospital provenían de censales como ya sucedía en hospitales grandes como la Santa Cruz de Barcelona. Esta diferencia deriva de la diversificación de ingresos posible gracias a prerrogativas que solo otorgaban ayuntamientos de capitales y el Rey (rifas, teatros, gestión de cementerio, etc...) y del pago por estancia recibido por la atención de militares. Véase: Barceló (2014, p. 315).

35. A partir del siglo XV la mayoría de municipios - y el Rey-, se financiaron mediante censales, puesto que los intereses eran del 6'66\%. En Valencia, entre 1536 y 1537 , el Ayuntamiento llegó a pagar al hospital y otros censalistas 42.472 sous por este concepto. Véase: Peset \& Graullera (1979, p. 115).

36. AHCV, «Fons Mercadé y Secció de pergamins».

37. Csordas (1990) expuso su teoría del embodiment (in-corporación) como paradigma de investigación antropológica. Puesto que no tiene una traducción óptima en lengua castellana, al utilizar dicho término los autores nos referimos a la interiorización de la población de una manera de pensar y de actuar en relación a fenómenos cotidianos.

38. Orden de destinar unos bienes a un fin determinado. En caso de destinar estos bienes a otras finalidades, el consignador o su familia conserva la potestad de recuperar dichos bienes.

39. AHCV, «Fons Mercadé». Un ejemplo es la consigna de nueve censales, con un capital de 13.703 libras y una pensión anual de 411, que Ramón Yxart i Jané hizo en 1814 a favor del hospital de Valls.

40. En Cataluña la expresión escanyapobres es sinónimo de usurero.
41. La palabra hinterland proviene del idioma alemán y significa, literalmente, tierra interna o posterior a una ciudad, puerto, etc. En un sentido más amplio al anterior, el término se refiere a la esfera de influencia de un asentamiento. En nuestro caso, utilizamos el concepto para delimitar el área para la cual la ciudad referida se convierte en el nexo comercial de ésta.

42. Fórmula que figura en todas las actas notariales de la misma naturaleza y, de esta manera, da nacimiento al uso que le permite ser considerada como sobrentendida en los contratos donde no esté expresamente inserta.

43. Esta ley expropió y privatizó los patrimonios de los hospitales públicos. Para el caso tarraconense, véase: Rovira (1990).

44. A diferencia del caso catalán, las desamortizaciones causaron la pérdida de autonomía económica y el cierre de la mayoría de los hospitales del resto de España, pasando los establecimientos supervivientes a manos de las diputaciones provinciales (Herr, 1962). Para el caso de Burgos, como uno de los ejemplos paradigmáticos, véase: Carasa (1986, pp. 9-40)

45. En el Hospital de la Santa Creu de Barcelona, los inventarios de bienes de 1821 (Danón, 1978, p. 65) y los rendimientos de los activos de 1847 (Pérez, 2003: 35) sugieren que las leyes desamortizadoras se aplicaron de forma muy endeble o afectaron de forma superficial a las propiedades y bienes de dicho hospital.

46. Para profundizar a nivel de Tarragona, véase: Fuentes et al., (2012).

47. Arxiu Històric Municipal de Valls (AHMV), "Actes Municipals, 13.12.1857»

48. AHMV, «Actes Municipals, 19.07.1858»

49. Con la excepción del propio edificio del hospital y del teatro.

50. AHCV, «Documents diversos 1800-1860. Carta de los administradores del hospital al Governador Civil, 31.05.1860».

51. AHCV, «Fons Mercadé, Proclamación Habitants de la vila de Valls e son terme, 01.03.1814».

52. AHMV, «Actes Municipals, 03.07.1833».

53. AHCV, «Documents Diversos 1800-1860, Registro del Archivo del Hospital Civil de Valls».

54. Una primera aproximación del presente artículo fue expuesta en: Barceló \& Comelles, (2014, pp. 347-352). 


\section{BIBLIOGRAFÍA}

Adserà, Josep (1994), La casa de recollides de Tarragona. Primera ampliació de l'hospital any 1764. Breu estudi sobre els espolis $i$ vacants. Tarragona, Associació Amics Hospital de Sant Pau i Santa Tecla.

Amelang, James S. (1986), La formación de una clase dirigente: Barcelona, 1490-1714. Barcelona, Ariel.

Anguera, Pere (1990), Hospital de Sant Joan de Reus, 12401990. Hospital de Sant Joan de Reus.

Assier-Andrieu, Louis (1989), "Le peuple et la loi. Anthropologie historique des droits paysans en Catalogne française", Anthropologie et Sociétés, 13 (1), pp. 175-187.

Barceló, Josep (2014), Poder local, govern i assistència pública: el cas de Tarragona. Tarragona, Universitat Rovira i Virgili.

Barceló, Josep; Comelles, Josep M. (2014), “Hospitales, economía política y la identidad cultural catalana". En: Campos, Ricardo; González, Ángel; Porras, Mạ Isabel; Montiel, Luis (eds.), Medicina y poder político (XVI Congreso de la Sociedad Española de Medicina. Madrid, 11-13 junio 2014). SEHM y Facultad de Medicina de la Universidad Complutense de Madrid, pp. 347-352.

Barceló, Josep (2015), “El proceso de fusión hospitalaria en la ciudad de Tarragona (1464)", Medicina e Historia, 1, pp. 4-19.

Betrán, Jose Luís (1996), La peste en la Barcelona de los Austrias. Lleida, Milenio.

Bonnassie, Pierre (1979-1981), Catalunya mil anys enrera (s. $X-X I)$. Barcelona, Edicions 62.

Borrell, Miquel (2005), Caritat, beneficència, solidaritat: I'Hospital de Sant Feliu de Guíxols (Del s. XIV al s.XX). Àrea de Cultura de l'Ajuntament de Sant Feliu de Guíxols.

Carasa, Pedro; Enciso, Luís Miguel (1985), El sistema hospitalario español en el siglo XIX: de la asistencia benéfica al modelo sanitario actual. Valladolid, Universidad, Secretariado de Publicaciones, D.L.

Carasa, Pedro (1986), "Desamortización y beneficencia: efectos de la desamortización de Madoz sobre el sistema hospitalario burgalés", Desamortización y Hacienda Pública, 2, pp. $9-40$

Carasa, Pedro (1987), Pauperismo y Revolución Burguesa (Burgos, 1750 -1900). Valladolid, Siglo XXI.

Carasa, Pedro (1988), Crisis del Antiguo Régimen y Acción Social en Castilla. Valladolid, Junta de Castilla y León.

Carasa, Pedro (1990), "La asistencia social en el siglo XVIII español: estado de la cuestión". En: Coloquio Internacional Carlos III y su Siglo: actas, Vol.1, (Cincuenta años de historiografía sobre el siglo XVIII). Madrid, Universidad Complutense, pp. 425-452.

Castejón, Natividad (2007), Aproximació a l'estudi de l'hospital de la Santa Creu de Barcelona. Repertori documental del segle XV. Barcelona, Fundació Noguera.

Cid, Felip; Gorina, Núria; Sánchez Aldeguer, Josep (1993), L'Hospital de l'Esperit Sant. Un exemple de l'evolució assistencial a Catalunya. Santa Coloma de Gramanet, Fundació Hospital de l'Esperit Sant.

Comelles, Josep M.; Daura, Angelina; Arnau, Marina; Martín, Eduardo (1991a), L'Hospital de Valls. Assaig sobre l'estructura i les transformacions de les institucions d'assistència. Valls, Institut d'Estudis Vallencs.

Comelles, Josep Maria; Daura, Angelina; Arnau, Marina; Martín, Eduardo (1991b), "L'hospital com a institució de crèdit: el cas de I'hospital de Valls". En: Jordà, Antòn. (ed.) Quaderns d'Història Contemporània. Homenatge a María Antonia Ferrer Bosch. Lleida, Poblagrafic, pp. 45-71.

Comelles, Josep Mạ (2006), Stultifera Navis. La Locura, el Poder y la ciudad. Lleida, Milenio.

Comelles, Josep M. (2013a) "Hospitals, Political Economy and Catalan Cultural Identity". En: Bonfield, Christopher; Reinarz, Joanthan; Huguet-Termes, Teresa (eds.) Hospitals and Communities, 1100-1960. Oxford, Peter Lang, pp. 183-208.

Comelles, Josep M.; Alemany, Silvia; Francès, Laura (2013b) De les iguales a la cartilla. El regiment de la cosa pública, la medicalització i el pluralisme asistencial a la Vall d'Aro. Barcelona, Departament de Cultura de la Generalitat de Catalunya.

Comelles, Josep M. (2014), "The care of strangers or the care of citizens? Culture, law and the political economy of care". En: Medical Anthropology at Home, 8th Meeting: transformations and the politics of care. Bertinoro, 29-31 maig de 2014.

Conejo, Antoni (2010), "La financiación de los hospitales de la Corona de Aragón durante la baja edad media: condiciones sociales, económica y espirituales". En: Cavachiocchi, Simoneta (ed.) Le interazioni fra economia e ambiente biológico nell'Europa preindustriales, secc.XIII-XVIII (Atti della XLI Settimana di Studi. Prato, 26-30 aprile 2009). Firenze, Istituto Internazionale di Storia Economica "F. Datini" \& Firenze University Press, pp. 437-44.

Constantelos, Demetrios J. (1968), Byzantine Philantropy and Social Welfare. New Brunswick, Rutgers University Press.

Constantelos, Demetrios J. (1992), Poverty, Society and Philanthropy in the Late Medieval Greek World. New Rochelle, Aristide D. Caratzas.

Csordas, Thomas (1990), "Embodiment as a Paradigm for Anthropology”, ETHOS, 18 (1), pp. 5-45. 
Cuadrada, Coral (2003), “Pobresa, marginació i sexe a l'edat mitjana". En: Piñol, Daniel (coord.), La història dels altres: exclusió social i marginació a les comarques tarragonines: segles XIII-XX. Centre d'Estudis Històrics i Socials Guillem Oliver del Camp de Tarragona, pp. 21-42.

Cubells, Josefina (1989), Una documentació inèdita: l'inventari dels censals de l'Hospital de sant Pau i santa Tecla de Tarragona (segles XV-XIX). Una aproximació vers un catàleg. Actes I Jornada Història Medicina Tarraconense, vol. II, Tarragona, Hospital de Sant Pau i Santa Tecla, pp. 6-69.

Danón, Josep (1978), Visió Històrica de l'Hospital de Santa Creu de Barcelona. Barcelona, Publicacions de la Fundació Salvador Vives.

Diana, Esther (2010), “Non solo carità. L'ospedale di Santa Maria Nuova di Firenze: un risultato imprenditoriale (12851427)", Ricerche Storiche, 40 (1), pp. 5-37.

Eiximenis, Francesc (1927), Regiment de la cosa pública [ed. or. 1385]. Barcelona, Els nostres clàssics.

Fernández, Asunción (1987), El Hospital Real y General de Nuestra Señora de Gracia de Zaragoza, en el siglo XVIII. Zaragoza, Institución Fernando el Católico.

Fernández Sevillano, Jaume (2003), “Comptabilitat interna de I'hospital general de Santa Creu de Barcelona (1401-1517): un llibre de comptes recuperat". En: Fernández, Jaume, Comptabilitat de costos a Catalunya abans de la partida doble: tres recerques històriques. Universitat de Barcelona, pp. 79-106.

Ferrer Alòs, Llorenç (1979), “L’Esglèsia com a institució de crèdit: les quotidianes distribucions de la Seu de Manresa els segles XVIII i XIX", Recerques: Història, economia i cultura, 18 , pp. 7-46

Ferrer Alòs, Llorenç (1983), "Censals, vendes a carta de gracia i endeutament pagès al Bages (s. XVIII)", Estudis d'Història Agrària, 4, pp. 101-128.

Ferrer Alòs, Llorenç (1987), Pagesos, rabassaires $i$ industrials a la Catalunya Central (segles XVIII-XIX). Barcelona, Edicions de l'Abadia de Montserrat.

Freidson, Eliot (1963), The Hospital in Modern Society. New York, Free Press of Glencoe.

Fontana, Josep (2014), La formació d'una identitat. Una història de Catalunya. Vic, Eumo Editorial.

Fuentes, Manel; Quijada, Joan; Sánchez, Neus (2012), Memòria del setge i ocupació de Tarragona. La Guerra del Francès en els fons documentals de l'Arxiu Històric Arxidiocesà de Tarragona (1808-1814). Barcelona, Rafael Dalmau.

García Ballester, Luis; McVaugh, Michael R.; Rubió Vela, Agustín (1989), Medical Licensing and Learning in Fourteenth-Century Valencia. Philadelphia, The American Philosophical Society.
García Guerra, Delfín (1983), El Hospital Real de Santiago (1499-1804). A Coruña, Fundación Pedro Barrie de la Maza.

Grieco, Anthony J.; Sandri, Lucia (eds.) (1997), Ospedali e città. L'Italia del Centro-Nord, XIII-XVI secolo. Firenze, Le Lettere.

Henderson, John (2001), "Healing the body and saving the soul: hospitals in Renaissance Florence. Renaissance Studies", Journal of the Society for Renaissance Studies, 15 (2), pp. 188-216.

Herr, Richard (1962), España y la revolución del siglo XVIII. Madrid, Aguilar.

Huguet, Teresa; Verdés, Pere; Arrizabalaga, Jon; Sánchez, Manuel (eds.) (2014), Ciudad y hospital en el Occidente europeo (1300-1700). Lleida, Milenio.

Imbert, Jean (1947), "Les hôpitaux en droit canonique", Revue d'histoire de l'Église de France, 35, pp. 86-92.

Juncosa, Eduard (2014), Estructura y dinámicas de poder en el señorío de Tarragona: creación y evolución de un dominio compartido (ca. 1118-1462). Madrid, Universidad Complutense.

López Alonso, Carmen (1988), Locura y Sociedad en Sevilla: Historia del Hospital de los Inocentes (1436-1840). Sevilla, Diputación provincial.

López Terrada, M.Luz (1999), "Health Care and poor relief in the crown of Aragon". En: Grell, Ole Peter; Cunningham, Andrew; Arrizabalaga, Jon (eds.) Health Care and poor relief in Counter-Reformation Europe. London, Routledge, pp. 177-200

Lluch, Ernest (1974), El Pensament econòmic a Catalunya. Barcelona, Ed.62.

Marino, Salvatore (2014), Ospedali e città nel Regno di Napoli. Le Annunziate: istituzioni, archivi e fonti. (secc. XIV-XIX). Nápoles, Biblioteca dell'Archivio storico italiano, vol.35.

Miller, Timothy S. (1997), The Birth of Hospital in the Byzantine Empire. Baltimore, Johns Hopkins University Press.

Miquel, José M.; Sánchez, José (1959), Los hospitales de Tarragona. Diputació de Tarragona.

Morelló, Jordi (2008), Municipis sota la senyoria dels creditors censals: la gestió del deute públic a la baronia de la llacuna (segle XV). Barcelona, Fundació Noguera.

Morelló, Jordi (2014), "Finanzas hospitalarias y deuda pública: los censales de la Santa Creu de Barcelona en torno a 1500". En: Huguet, Teresa; Verdés, Pere; Arrizabalaga, Jon; Sánchez, Manuel (eds.), Ciudad y hospital en el Occidente europeo (1300-1700). Lleida, Milenio, pp. 211-261.

Nutton, Vivian (1977), "Archiatri and the Medical Profession in Antiquity", Papers of the British School at Rome, 45, pp. 191-226. 
Nutton, Vivian (2004), Ancient Medicine. London \& New York, Routledge.

Ourliac, Paul (1989), "Le droit social du moyen âge". En: Harouel, Jean-Louis (publ.) Histoire du droit social : mélanges en hommage à Jean Imbert. París, PUF, pp. 447-456.

Patlagean, Éveline (1977), Pauvreté économique et pauvreté sociale à Byzance, $4 e-7 e$ siècles. The Hague, Mouton.

Pérez, Manuel (2003), La privatització de la follia: I'assistència psiquiàtrica a Catalunya durant el segle XIX. Barcelona, Publicacions de l'Abadia de Montserrat.

Peset, Mariano; Graullera, Vicente (1979), "Els censals i la propietat de la terra al segle XVIII valencià", Recerques: Història, economia i cultura, 18, pp. 107-138.

Pladevall, Antoni (2000), Hospital de la Santa Creu de Vic. Història d'una institució assistencial. Vic, Hospital de la Santa Creu.

Reventós, Josep (1996), Els hospitals i la societat catalana. Barcelona, Hacer.

Risse, Guenter B. (1999), Mending bodies, saving souls: a history of hospitals. Oxford University Press.

Rovira, Salvador J. (1990), Les desamortitzacions a les comarques meridionals del Principat. Barcelona, Dalmau.

Rubió, Agustín (1984), Pobreza, enfermedad y asistencia hospitalaria en la Valencia del siglo XV. Valencia, Institució Alfons el Magnànim, D.L.

Salrach, Josep M (1987), El procés de feudalització (segles IIIXII). Barcelona, Edicions 62, vol. II.

Salrach Josep, M. (2013), Justícia i poder a Catalunya abans de I'any mil. Barcelona, Grup 62.

Sobrequés, Santiago; Sobrequés, Josep (1973), La guerra civil catalana del segle XV. Barcelona, Edicions 62, vol. I.

Soronellas, Montserrat (1990), “Endeutament i reproducció domèstica als segles XVIII i XIX", Butlletí del Cercle d'Estudis Històrics i Socials Guillem Oliver, 7, pp. 8-10.
Tello, Enric (1986), "La utilització del censal a la Segarra del setcents: crèdit rural i explotació usurària", Recerques: Història, economia i cultura, 18, pp. 47-71.

Tello, Enric (2004), "La fi del censal: reducció de l'interès o vaga de pensions? (1750-1861)", Butlletí Societat Catalana d'Estudis Històrics, 15, pp. 125-155.

Terradas, Ignasi (1984), El món històric de les masies. Barcelona, Curial.

Terradas, Ignasi (2005), “Els orígens de la institució d'Hereu a Catalunya: vers una interpretació contextual", Quaderns-e de l'Institut Català d'Antropologia, 6, pp. 65-98.

Torras Ribé, Josep M. (1983), Els municipis catalans del l'Antic Règim (1453-1808). Procediments electorals, òrgans de poder i grups dominants. Barcelona, Curial.

Torras Ribé, Josep M. (2003), Los mecanismos del poder. Los Ayuntamientos catalanes durante el siglo XVIII. Barcelona, Crítica.

Valenzuela, José; Moreno, Rosa M.; Girón, Fernando (2008), El Hospital Real de Granada y sus Constituciones de gobierno (1593-1857). Asistencia a los pobres y regulación social. Universidad de Granada.

Vilar, Pierre (1964-68), Catalunya dins l'Espanya moderna, 4 vols. Barcelona, Curial Edicions catalanes S.A.

Villanueva, Jaime (1821), Viaje literario a las iglesias de España. Madrid, Imprenta de Fontanet.

Zamorano, Ma Luísa (1997), Historia del Hospital de San Juan Bautista de Toledo durante el siglo XVI. Toledo, Instituto Provincial de Investigaciones y Estudios Toledanos.

Zarzoso, Alfons (2003), La pràctica mèdica a la Catalunya del segle XVIII. Barcelona, Universitat Pompeu Fabra.

Zarzoso, Alfons (2006), L'exercici de la medicina a la Catalunya de la II-Iustració. Manresa, Publicacions de l'Arxiu Històric de les Ciències de la Salut. 